\title{
Alan Cowan: Buprenorphine from the bench to the bedside-Personal notes
}

\author{
Saadet Inan, MD, PhD; Michael Guarnieri, PhD, MPH
}

In 2005, Bob Adams, the Chief Veterinarian at Johns Hopkins, wondered if sustained release technology could be used to improve postsurgical analgesia for animal medicine. Henry Brem, Director of the Hunterian Laboratories, had organized an international consortium to advance therapy for brain tumors and stroke. The Hunterian had over 20 years of experience with the safety and effectiveness of neutral lipids, phospholipids, carbohydrates, gels, polymers, and assorted devices for sustainedrelease drug delivery. We had the technology. What was the best pharmacology? Buprenorphine was the obvious analgesic. Reports of adverse events in the veterinary literature were rare.

If buprenorphine were safe, what about combinations of the drug with long-acting carrier systems? Few scientists would be willing to jeopardize decades of vascular disease, cancer, or orthopedic research, for example, by introducing a new analgesic or anesthetic protocol. A consensus at the Hunterian was polymer carriers could be difficult due to inflammatory responses. Based on safety, lipid carriers appeared to be a default choice. Reckitt Benckiser, the successor corporation to Reckitt \& Coleman, had become a leading buprenorphine manufacturer. A phone call to the technology office regarding drug stability led to a recommendation to consult Alan Cowan. Professor Cowan was just up the road in Philadelphia at Temple University.

Alan Cowan's name was familiar because it was a basis of the buprenorphine literature. But would he help a stranger who knew so little about the drug? A phone call quickly confirmed that I [MG] was not a stranger, rather a colleague and so typical of his professional relations, he generously offered to help. He

DOI:10.5055/jom.2021.0637

(C) 2021 Journal of Opioid Management,

All Rights Reserved. had the same idea for a long-acting product while riding his bike many evenings and weekend to the laboratory to monitor dose schedules. Years later, I asked if my connection with Hopkins Hunterian Laboratory had helped as the original Hunterian Laboratory was at the University of Glasgow? "Of course," he said (Figure 1).

Alan received degrees in pharmacy from the University of Glasgow (1964) and the Royal College of Science and Technology, and his PhD in pharmacology from the University of Strathclyde, Glasgow, in 1968. He took a position as a Section Leader for Reckitt \& Colman (hereafter referred to as Reckitt) in Hull, England. He worked with John Lewis to commercialize drugs Reckitt scientists had developed to be as good as morphine but less addictive. An introduction to the history of this work has been described by Nancy Campbell and Anne Lovell. ${ }^{1}$

The study of pain in animals was a developing field. Behavioral observations of pain and opiate withdrawal symptoms were highly subjective. Alan used thermal latency trials as one test of drug

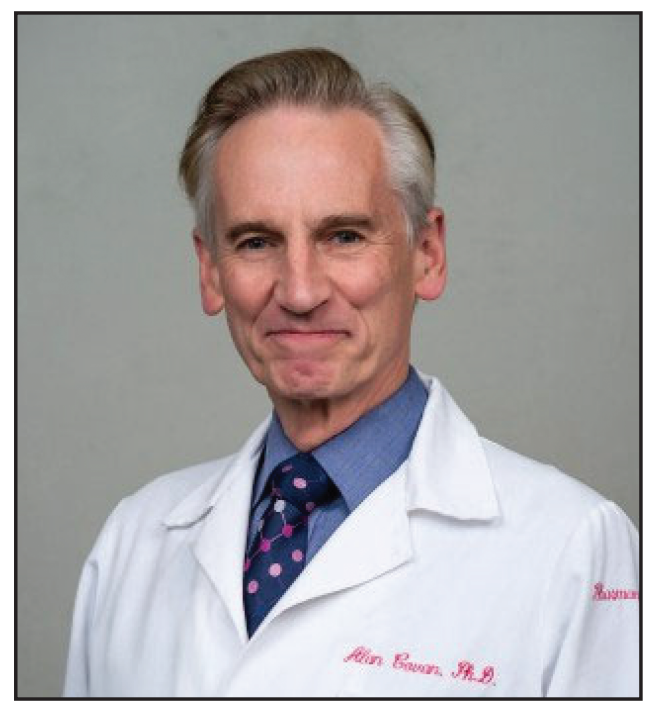

Figure 1. Alan Cowan, PhD. 
efficacy. Withdrawal signs in competitive dosing studies were another. Prospects for the drug's future seemed high as rodent studies demonstrated that buprenorphine was 20-40 times more potent than morphine and orders of magnitude safer. The Reckitt team could not find a lethal subcutaneous dose in rats or mice. Establishing an oral lethal dose in rats was equally problematic. The calculated therapeutic index (LD50/ED50) for intravenous morphine and buprenorphine in rats was, respectively, 464 versus $12,313$.

Virtually all Alan's works on the safety and efficacy of buprenorphine were published after he left Reckitt in 1975, and then joined Temple University's highly respected Pharmacology Department. Despite buprenorphine's extraordinary safety profile, morphine was cheap and had better oral bioavailability. There were also lingering questions about buprenorphine's mode of action. Whether monitored by thermal latency tests in preclinical trials or patient reports in clinical studies, the analgesic effects of buprenorphine and plasma drug concentrations were frequently uncoupled. Comparisons of buprenorphine efficacy with morphine and methadone were complicated by what we now understand as the unique mixed agonist-antagonist properties of buprenorphine. Permission to publish the work probably was supported by Reckitt's decision to abandon further developmental research but maintain the drug for veterinary use.

Any reading of Cowan's toxicology studies defines a textbook lesson on drug development for a new analgesic., ${ }^{2,3}$ He consistently asked the right toxicology questions, a quality likely supported by his training as a pharmacologist. I had the honor of introducing Alan to the Blaustein Pain lecture series at Johns Hopkins. I described Dr. Cowan as the rare scientist who developed not one, but three drugs: buprenorphine for acute and chronic pain therapy, and for heroin detoxification. He later told me that he also thought of his work as developing three drugs: buprenorphine not only for analgesia and opioid use therapy but also as a tool to study the molecular activity of pain receptors, a strategy compellingly documented in numerous post-Reckitt publications. ${ }^{4-7}$

Meeting Alan has changed my life [SI] (and many other lives). I remember my first email to him asking whether I could work with him given my background as an MD from Turkey and lacking English fluency. Upon receiving the email, Alan called and left me a message, asking whether I could visit him in the next few days. This was right just before Christmas of 2000 when I met him and my journey in science began. In these 20 years, I have had the privilege to have a mentor and work alongside a hard-core opioid pharmacologist. I was his colleague, last PhD student, and friend. To highlight how hard working and dedicated he was to his field, he emailed me the night before he died to answer a question I had.

Recent knowledge on kappa opioid receptors (KORs) and ligands effective on KORs made buprenorphine the preferred option over other analgesics for treatment of chronic pain and other opioid use disease treatment medications like methadone. Buprenorphine is not only as a partial $\mu$ opioid receptor agonist but also a KOR antagonist. Recent studies indicate that KORs and its endogenous ligands, Dynorphins, play an important role in emotions, stress, anxiety, and depression-like behaviors accompanied with chronic pain and dependence. ${ }^{8-10}$ Administration of KOR antagonists to rodents with chronic pain alleviated anxiety and depression-like behavior. ${ }^{10}$ Furthermore, clinical studies with buprenorphine report that it is effective to relieve stress, anxiety, and depression. ${ }^{11-14}$

Alan's contributions to science and humanity are not restricted to pain and opioid use disorder treatments. Debra Gmerek and Alan introduced a rat model that allowed quantitative measurements of scratching behavior (as itch-like behavior) by intracerebroventricular administration of bombesin, a tetradecapeptide originally isolated from frog skin in $1983 .{ }^{15}$ Bombesin is a homolog of mammalian gastrin-releasing peptide, subsequently identified as a mediator for itch. ${ }^{16}$ Debra and Alan $^{17}$ also showed for the first time that KOR agonists alleviate bombesin-induced itch-like behavior. Later, George Kehner and then myself continued studies on involvement of KORs in itch and antipruritic effects of KOR agonists on acute and chronic itch rodent models. ${ }^{18-23}$ The studies from his lab led to one of the most exciting discoveries that dynorphine A acts as a neuromodulator for inhibiting itch in the dorsal horn of the spinal cord. ${ }^{24}$ Today, KOR agonists are in clinic and clinical studies to treat chronic itch associated with kidney disease, liver disease, and some skin diseases like atopic dermatitis. ${ }^{25-27}$

We lost a great scientist, mentor, colleague, and friend. Alan is missed and will continue to be missed. His legacy and contributions to medical science will persist. 


\section{ACKNOWLEDGMENTS}

The authors thank Fiona Cowan for her help in organizing the material and manuscript. IS research is supported by National Institute of Health/National Institute on Drug Abuse P30 Grant DA 013429.

Saadet Inan, MD, PhD, Center for Substance Abuse Research, Lewis Katz School of Medicine at Temple University, Philadelphia, Pennsylvania.

Michael Guarnieri, PhD, MPH, Pediatric Neurosurgery, Johns Hopkins Neurosurgical Hunterian Laboratory, Baltimore, Maryland. ORCID: https://orcid.org/OOOO-00023079-6746.

\section{REFERENCES}

1. Campbell ND, Lovell AM: Addiction reviews the history of the development of buprenorphine as an addiction therapeutic. Ann N Y Acad Sci. 2012; 1248: 124-139. DOI:10.1111/j.17496632.2011.0635.x.

2. Cowan A, Doxey JC, Harry EJ: The animal pharmacology of buprenorphine, an oripavine analgesic agent. BrJ Pharmacol. 1977; 60(4): 547-554. DOI:10.1111/j.1476-5381.1977.tb07533.x.

3. Cowan A, Lewis JW, Macfarlane IR: Agonist and antagonist properties of buprenorphine, a new antinociceptive agent. $\mathrm{BrJ}$ Pharmacol. 1977; 60(4): 537-545. DOI:10.1111/j.1476-5381.1977. tb07532.x.

4. Cowan A: Use of the mouse jumping test for estimating antagonistic potencies of morphine antagonists. J Pharm Pharmacol. 1976; 28(3): 177-182. DOI:10.1111/j.2042-7158.1976.tb04126.x.

5. Porreca F, Cowan A, Raffa RB, et al.: Estimation in vivo of the receptor constants of morphine in naive and morphine-tolerant rats. Life Sci. 1982; 31(20-21): 2355-2358. DOI:10.1016/00243205(82)90155-2.

6. Porreca F, Raffa RB, Cowan A, et al.: A comparison of the receptor constants of morphine and ethylketocyclazocine for analgesia and inhibition of gastrointestinal transit in the rat. Life Sci. 1982; 31(18): 1955-1961. DOI:10.1016/0024-3205(82)90034-0.

7. Tallarida RJ, Cowan A: The affinity of morphine for its pharmacologic receptor in vivo. J Pharmacol Exp Ther. 1982; 222(1): 198-201. PMID: 6283067.

8. Knoll AT, Carlezon Jr WA: Dynorphin, stress, and depression. Brain Res. 2010; 1314: 56-73.

9. Chavkin C, Koob GF: Dynorphin, dysphoria, and dependence: The stress of addiction. Neuropsychopharmacology. 2016; 41: 373-374.

10. Liu S, Pickens S, Burma NE, et al.: Kappa opioid receptors drive a tonic aversive component of chronic pain. J Neurosci. 2019; 39(21): 4162-4178.

11. Bershad AK, Jaffe JH, Childs E, et al.: Opioid partial agonist buprenorphine dampens responses to psychosocial stress in humans. Psychoneuroendocrinology. 2015; 52: 281-288. DOI:10.1016/j.psyneuen.2014.12.004.

12. Browne CA, Falcon E, Robinson SA, et al.: Reversal of stressinduced social interaction deficits by buprenorphine. Int J Neuropsychopharmacol. 2018; 21(2): 164-174.

13. Li W, Sun H, Chen H, et al.: Major depressive disorder and kappa opioid receptor antagonists. Transl Perioper Pain Med. 2016; 1(2): 4-16.

14. Bershad AK, Ruiz NA, de Wit H: Effects of buprenorphine on responses to emotional stimuli in individuals with a range of mood symptomatology. Int J Neuropsychopharmacol. 2018; 21(2): 120-127.

15. Gmerek DE, Cowan A: An animal model for preclinical screening of systemic antipruritic agents. J Pharmacol Methods. 1983; 10: 107-112.

16. Sun YG, Chen ZF: A gastrin-releasing peptide receptor mediates the itch sensation in the spinal cord. Nature. 2007; 448: 700-703.

17. Gmerek DE, Cowan A: In vivo evidence for benzomorphanselective receptors in rat. J Pharmacol Exp Ther. 1984; 230: 110115.

18. Cowan A, Kehner GB: Antagonism by opioids of compound 48/80-induced scratching in mice. Br J Pharmacol. 1997; 122 (suppl.): 169P.

19. Cowan A, Inan S, Kehner GB: GNTI, a kappa opioid receptor antagonist, causes compulsive scratching in mice. Pharmacologist. 2002; 44: A51.

20. Inan S, Cowan A: Kappa opioid agonists suppress chloroquine-induced scratching in mice. Eur J Pharmacol. 2004; 502: 233-237.

21. Inan S, Cowan A: Nalfurafine, a kappa opioid receptor agonist, inhibits scratching behavior secondary to cholestasis induced by chronic ethynylestradiol injections in rats. Pharmacol Boichem Behav. 2006; 85: 39-43.

22. Inan S, Dun NJ, Cowan A: Nalfurafine prevents GNTI- and compound 48/80-induced spinal cfos expression and attenuates GNTI-elicited scratching behavior in mice. Neuroscience. 2009; 163: 23-33.

23. Inan S, Torres-Huerto A, Jensen LE, et al.: Nalbuphine, a kappa opioid receptor agonist and mu opioid receptor antagonist attenuates pruritus, decreases IL-31, and increases IL-10 in mice with contact dermatitis. EurJ Pharmacol. 2019; 864: 172702.

24. Kardon AP, Polgar E, Hachisuka J, et al.: Dynorphin acts as a neuromodulator to inhibit itch in the dorsal horn of the spinal cord. Neuron. 2014; 82: 573-586.

25. Kumagai H, Ebata T, Takamori K, et al.: Efficacy and safety of a novel $\mathrm{K}$-agonist for managing intractable pruritus in dialysis patients. Am J Nephrol. 2012; 36: 175-183.

26. Fishbane S, Jamal A, Munera C, et al.: A phase 3 trial of difelikefalin in hemodialysis patients with pruritus. $N$ Engl J Med. 2020; 382: 322-232.

27. Available at https://www.trevitherapeutics.com/pipeline/. Accessed December 15, 2020. 